\title{
ELOGIO DE LA DISCULPA. CONOCIMIENTO Y PREJUICIO EN LAS GLOSAS DE PEDRO DE TOLEDO A SU TRADUCCIÓN DE LA GUÍA DE PERPLEJOS
}

\section{In Praise of Apology. Knowledge and Prejudice in Pedro de Toledo's Glosses to his Translation of Maimonides's Guide of the Perplexed}

\author{
José Antonio Fernández López
}

Universidad de Murcia

\section{Resumen}

El objetivo del presente artículo es indagar en una problemática concreta vinculada a la traducción cuatrocentista de Pedro de Toledo de la Guía de Perplejos. Los prólogos y epílogos del traductor a los tres libros del Mostrador e enseñador de los turbados, las glosas insertadas por mano de escribano en el texto son la expresión de una idea de ciencia y de conocimiento gestada en el contexto humanista del siglo XV castellano, así como de sus fuentes árabes y judías; también, de un mundo de prejuicios y de ignorancia, de cuestionamiento cultural del valor de esas mismas fuentes, fundamentalmente las judías. En un tiempo de crisis y de transformación de la sociedad hispana, estas glosas y comentarios, la traducción en su conjunto, son el reflejo de un mundo de paradojas culturales, de aspiración al conocimiento y de limitaciones humanas.

Palabras clave

Maimónides; Pedro de Toledo; conocimiento; Filosofía; traducción; comentario

\begin{abstract}
The aim of this paper is to examine a specific problem related to the $15^{\text {th }}$-century translation of Maimonides's Guide of the Perplexed into Castilian, the oldest version in a vulgar language of the Moreh nevukhim, under the title Mostrador e enseñador de los turbados. The translator's prologues and epilogues to the three books of the Guide and the glosses inserted in the text articulate the idea of science and knowledge as it was developed in the context of Spanish Humanism. At the
\end{abstract}


same time, they are the expression of a world of prejudice and ignorance in the wide spectrum of the questioning of these cultural traditions, mainly the Jewish tradition. In a time of crisis and transformation of Hispanic society, these glosses and commentaries, and the translation as a whole, were the reflection of a cultural paradox of aspirations and limits.

\section{Keywords}

Maimonides; Pedro of Toledo; Knowledge; Philosophy; Translation; Commentary

\section{Introducción. Dalālat, Môrèh, Mostrador}

La empresa traductológica vinculada a la transmisión de la Guía de perplejos da cuenta de una fascinante dialéctica entre la particularidad de las enseñanzas de la obra y sus rasgos de universalidad. En esta aventura cultural, que se inicia entre los años 1199-1204 con la traducción de Samuel ibn Tibbón del original árabe (Dalālat al-ha’ìrim) al hebreo (Môrèh Nebûkîm), se pondrá progresivamente de manifiesto una certeza asociada a la singularidad del texto escrito por Maimónides: el valor intelectual de una obra donde la hermenéutica racional aporta una resolución al problemático diálogo ferazón, que trasciende, aunque no fuera esta su intención, los límites de un marco religioso concreto. La traducción de ibn Tibbón, sancionada por el propio autor ${ }^{1}$, no sólo permitirá la recepción por parte del judaísmo de la diáspora ajeno a la cultura arábiga de una de las obras capitales del pensamiento judío, sino que además sentará las bases del lenguaje filosófico hebreo durante siglos. En el privilegiado intercambio epistolar entre el autor y el primer traductor del Môrèh, Maimónides manifiesta que el principio que debe regir toda traducción es evitar «transcribir palabra por palabra, preservando tanto el orden del texto como el de los términos», optando por «comprender, en primer lugar, el sentido del original y después escribirlo, comentarlo y explicarlo bien en la otra lengua ${ }^{2}$. Un principio traductológico que, como veremos posteriormente, nos va a aportar un importante elemento de juicio para el análisis de la propia traducción de Pedro de Toledo. Como relevante resultará, también, para esta empresa cuatrocentista, la segunda de las versiones hebreas de original árabe de la Guía. Casi de forma contemporánea a ibn Tibbón, el poeta Yehudá Al-Harīzī vierte al hebreo la obra maestra maimonidiana con un refinado estilo que busca la comprensión general por encima de la precisión terminológica. En parte por tal motivo, esta traducción será la base para

\footnotetext{
${ }^{1}$ Maimónides, Epístola a Shemuel Ibn Tibbón, ed. M.J. Cano y D. Ferre, Cinco epístolas de Maimónides, Barcelona, Riopiedras, 1988, p. 114. Ediciones de referencia de la Guía: Maimónides, Guía de perplejos, ed. de D. Gonzalo Maeso, Madrid, Trotta, 2005; Moreh nevukhim, ed. Y. Even-Shmuel, Jerusalén, Mossad Harav Kook, 1987. Edición comentada y vocalizada del texto de Ibn Tibbón, publicada en cuatro volúmenes a lo largo de cinco décadas. La versión más actual del texto tibbónida ha sido publicada recientemente (2019) por Feldheim Publishers, Nueva York; Moreh ha-Nevukim (Edición crítica y traducción del original árabe al hebreo moderno, M. D. Schwarz), Tel Aviv, Tel Aviv University Press, 2002.

${ }^{2}$ Ibid., p. 115.
} 
posteriores versiones en latín y en lenguas romances, incluida la primera versión castellana ${ }^{3}$. Estas dos famosas traducciones generaron un sinfín de discusiones desde su aparición, un apasionante campo de batalla traductológico y hermenéutico, a la vez que también ideológico ${ }^{4}$. Lo esencial para nosotros, es que ambas traducciones del original árabe de Maimónides terminaron solapando el original. Para las siguientes generaciones de judíos hispanos, cada vez más alejados de la esfera de influencia islámica por el propio devenir de la historia peninsular, las dos versiones hebreas se convertirán en referencia exclusiva, como también para los eruditos cristianos que se acerquen con interés científico y admiración a la obra del cordobés.

Llevada a cabo por Pedro de Toledo 5 , tras un encargo de Gómez Suárez de Figueroa, hijo del maestre de la Orden de Santiago Lorenzo Suárez de Figueroa y cuñado de Íñigo López de Mendoza, Marqués de Santillana, el Mostrador e enseñador de los turbados es la primera traducción a una lengua moderna del Môrèh Nebûkîm ${ }^{6}$. Característica singular de esta obra, escrita en el crepúsculo de un mundo de códices, manuscritos, copistas y escribanos, es la propia materialidad del único manuscrito conservado de la misma, el ms. 10289 de la Biblioteca Nacional, un tomo de 408×290 milímetros, de 141 folios, a dos columnas de 42-45 líneas por página, con títulos y capitales en rojo, letra de la primera mitad del siglo XV y encuadernación mudéjar. Una singularidad no formal o estética,

${ }^{3}$ Sobre el estilo y el rigor conceptual de la versión de Al-Harīzī , así como las implicaciones de esto, véase Friedländer, M., «The Moreh Nebuchim Literature», en Maimónides, The Guide for the Perplexed, ed. M. Friedländer, Nueva York, E. P. Dutton, 1904, pp. XXVIII-XXX; Bar-Lewaw, I., «Pedro de Toledo, el primer traductor español del More Nebujim», en VV.AA., Homenaje a Rodriguez Moñino, vol. 1, Madrid, Castalia, 1966, p. 57-59; Scheindlin, R.P., «Al-Harīzi 's Translation of the Guide of the Perplexed in Its Cultural Moment», en J. Stern, J. T. Robinson, \& Y. Shmesh (eds.), Maimonides' Guide of the Perplexed in Translation, Chicago, University of Chicago Press, 2019, pp. 75-78.

${ }^{4}$ Una descripción del marco controversial en torno a la Guía y a sus traducciones y comentarios en el judaísmo de los siglos XIII-XIV en I. De Souza, Rewriting Maimonides. Early Commentaries on the Guide of the Perplexed, Berlín/Boston, De Gruyter, 2018, pp. 8-10; 14-16; Rigo, C., «Dux neutrorum and the Jewish Tradition of the Guide of the Perplexed», en J. Stern, J.T. Robinson, \& Y. Shmesh (eds.), Maimonides' Guide, op. cit., pp. 98-102.

${ }^{5}$ Una síntesis de la problemática en torno a la identidad y el origen controversial del traductor, así como del contexto traductológico, en nuestra edición crítica del manuscrito. Cf. Maimónides, Mostrador e enseñador de los turbados. Traducción cuatrocentista de Pedro de Toledo, ed. J.A. Fernández López, Zaragoza, Riopiedras Ediciones, 2016, pp. 24-52.

${ }^{6}$ La traducción de los libros primero y segundo tiene como fecha de conclusión 1419, mientras que el libro tercero 1432. Mencionada la traducción de Pedro de Toledo en el catálogo de la biblioteca que los condes de Benavente tuvieron en el siglo XV, Fernando de Colón también consigna su existencia en su Registrum librorum, bajo el número 3282 (tomo de varios). De ninguno de estos dos manuscritos se tiene hoy noticia de su existencia. En 1882, al publicar José María Rocamora un Catálogo abreviado de los manuscritos de la biblioteca del Exclmo. Duque de Osuna e Infantado, al no 162, dio noticia de un códice del siglo XV que contenía el Môrèh traducido por Pedro de Toledo. Esta biblioteca de Osuna e Infantado contenía los manuscritos de Don Íñigo López de Mendoza, reunidos en su castillo de Guadalajara. Adquirida por el Estado Español en 1884, los manuscritos pasaron a la Biblioteca Nacional, y allí se halla en ms. 10289, correspondiente al Mostrador e enseñador de los turbados. 
sino vinculada a una suerte de reescritura infinita de la traducción, al poliédrico haz hermenéutico que parece brotar de las anotaciones marginales que acompañan $\mathrm{y}$, a veces, casi ocultan, el texto base. Así, por un lado, las «diferencias» entre la obra original y el texto traducido, la distancia que media entre la Dalälat al-ha'îrim, su doble transmisión como Môrèh nebûkîm, y el Mostrador e enseñador de los turbados, expresan la creatividad que resulta de una tensión entre eso que ha sido llamado généricité auctoriale, intrínseca e invariable, y la généracité lectoriale, fijada a la recepción del texto, una oposición que puede ser tan contrastada cuanto mayor distancia temporal o espiritual exista con el contexto original ${ }^{7}$. Por otro, las «variaciones» de esa misma lectura, plasmadas en centenares de glosas que conforman una suerte de «relectura insatisfecha» del texto plasmado en la traducción. En el centro de gravedad de este universo dialéctico, fraguado en el tránsito que va desde finales del siglo XII hasta comienzos del siglo XV, hallamos una red de intercambios conformada por el ámbito de origen, las incorporaciones y préstamos en el devenir del original, el contexto cultural de acogida y, junto a ello, una más que anónima confluencia de factores personales difícilmente discernibles.

Habiendo abordado en trabajos anteriores algunos de los aspectos hermenéuticos fundamentales vinculados al ms. $10289^{8}$, el objetivo del presente artículo es indagar en una problemática concreta vinculada a la empresa traductológica de Pedro de Toledo. Los prólogos y epílogos del traductor a los tres libros del Mostrador, las glosas insertadas por mano de un escribano al texto son la expresión de una idea de ciencia y de conocimiento gestada en el contexto humanista del siglo XV castellano; también, de un mundo de prejuicios y de ignorancia, de saberes velados, perdidos o premeditadamente olvidados por un intelectual converso al que la tradición de sus ancestros se le escapa o le resulta una carga intolerable. Vamos pues a analizarlos desde esta doble perspectiva, atendiendo a su marco histórico e ideológico, un tiempo y una sociedad que ya acaba de cerrar en Tortosa (1413-14) la última de las grandes disputas antitalmúdicas y que está cerca de iniciar el último capítulo de la historia de los judíos en las tierras peninsulares?

\section{Traducción, tradición y contexto}

La metodología de trabajo de Pedro de Toledo se desarrolla, tal como él mismo advierte en la introducción de su traducción, «segunt la costumbre» de su tiempo: «yo fare lo que deuo e seguire la rregla e costunbre de los trasladadores letrados que amj

${ }^{7}$ Schaeffer, J-M., Qu'est-ce qu'un genre littéraire, París, Éditions du Seuil, 1989, pp. 151-154.

${ }^{8}$ Cf. Fernández López, J.A., «Mostrador e enseñador de los turbados. Notas sobre el primer romanceado de la Guía de perplejos», Anales del Seminario de Historia de la Filosofía, 28 (2011), pp. 39-70.

${ }^{9}$ Un estudio histórico, crítico y doctrinal en Pacios López, A., La Disputa de Tortosa (vol. I), CSIC. Instituto Arias montano, Madrid-Barcelona, 1957. El segundo volumen recoge las actas latinas de esta disputa. 
son antiçipados $»^{10}$. El método de trabajo de los traductores cuatrocentistas bebía de fuentes perfectamente reconocibles, que se remontaban a los siglos anteriores. $\mathrm{Su}$ marco general, al margen de la diversidad de técnicas utilizadas, había sido establecido por San Jerónimo mediante el uso de la técnica del dictado. En esencia, consistía en un proceso de traducción dividido en dos momentos fundamentales: en primer lugar, se realizaba un borrador preparado por el escribano -en nuestro caso, tal como indica el propio traductor en el epílogo a la parte III de la obra, Alfonso Pérez de Cáceres- al dictado del traductor; una vez preparada esta çeda se añadían, si era preciso, las glosas, ya fuese de la mano del traductor, o al dictado por parte del escriba; con este material se redactaba la copia definitiva, en la cual podían incorporarse las glosas marginales en forma de amplificaciones ${ }^{11}$. Estas glosas, que son un elemento determinante en el ms. 10289, expresan una concepción de fidelidad al original difícilmente comprensible si utilizamos categorías descontextualizadas. Asociado de forma estrecha a la teoría y a la praxis exegética, establecía un «criterio de demarcación» entre la interpretación y la pura literalidad del texto. Ya San Jerónimo había marcado un punto de inflexión entre la práctica traductológica de los clásicos, supeditada a la imitatio, y el ejercicio exegético caracterizado como enarratio, el cual se servía de la glosa y la paráfrasis. Sus teorías sobre la traducción son una respuesta a las críticas recibidas por algunas de sus traducciones griegas. En la Epístola a Pamaquio, escrita a fines del siglo IV, acuña conceptos que serán claves para las traducciones medievales, tal como leemos en este fragmento de la traducción de Alonso de Cartagena: «en la interpretación de los libros griegos non curo de exprimir una palabra por otra, mas sigo el seso et efecto, salvo en las Sagradas Escripturas, porque allí la orden de las palabras trae misterio» ${ }^{12}$.

La búsqueda de la comprensibilidad en aras de una «fidelidad creativa», el «seso et efecto», expresa una opción hermenéutica de amplio recorrido y calado en las

${ }^{10}$ fol. 1r. Una digitalización del manuscrito (microform) en Lazar, M. (ed.), The Text and Concordance of B. N., Madrid, Ms. 10289. M. Maimonides' Mostrador e enseñador de los turbados (Pedro Toledo's Spanish Translation), Madison, HSMS, 1987. El texto impreso y sin aparato crítico en Maimónides, Guide for the Perplexed, ed. M. Lazar, Pedro de Toledo's Mostrador e enseñador de los turbados, Labyrintos, Culver City, 1989.

${ }^{11}$ Véase sobre esta cuestión: Buridant, C., «Translatio medievalis. Théorie et pratique de la traduction médiévale», Travaux de Linguistique et Littérature, 21 (1983), pp. 81-136; Cañizares Ferriz, P., «Técnicas de traducción en el siglo XV castellano: la novela de Diego de Cañizares a la luz de su original latino», Cuadernos de filología clásica. Estudios latinos, 24/1 (2004), pp. 57-62; Rubio Tovar, J., «Algunas características de las traducciones medievales», Revista de Literatura Medieval, 9 (1997), pp. 197-243; Russell, P.E., Traducciones y traductores en la Península Ibérica, Bellaterra, Universidad Autónoma de Barcelona, 1985, pp. 37-41.

${ }^{12}$ Una traducción y estudio crítico reciente de Ad Pammachium de optimo genere interpretandi en Bona, E., Le libertà del traduttore. L'epistola de optimo genere interpretandi di Gerolamo (Testo latino, introduzione, traduzione e note), Roma, Bonanno Editore, 2008. Cfr. la antología de Lafarga, F. (ed.), El discurso sobre la traducción en la historia, Barcelona, EUB, 1996, pp. 46-71. El texto de Cartagena en Santoyo, J.C., Teoría y crítica de la traducción: antología, Bellaterra, Universidad Autónoma de Barcelona, 1987, pp. 33-34. 
traducciones medievales. En virtud de esta metodología, la manipulación de la materia textual que en ella se propone consistirá tanto en una abbreviatio como una amplificatio del texto, tendentes ambas a hacer comprensible el contenido esencial del mismo. Junto a este, llamémosle, «esclarecimiento ontológico», las traducciones cuatrocentistas castellanas recurren a la estrategia del commentarium para adaptarse del modo más efectivo a la finalidad de la traducción o a la materia tratada, aunque también acuciadas por la evidente pobreza de la lengua romance frente a la lengua de los originales. Alfonso Fernández de Madrigal, el Tostado (1400-1455), obispo de Ávila, establece, a partir de la distinción ciceroniana ad verbum-ad sensum, la contraposición «interpretación-glosa» (o «exposición») ${ }^{13}$. Esta diferenciación tiene como finalidad, en el fondo, establecer un marco justificativo que permita asumir el valor que tiene el fenómeno de la paráfrasis, el comentario y la amplificación a la hora de superar la falta de correspondencia entre el castellano y las lenguas de los originales, dotar a las traducciones de intencionalidad didáctica, e inclusive, responder a la inquietud estética que pretende trasladar al romance la impronta del original.

La metodología y la intencionalidad traductológica de Pedro de Toledo pueden comprenderse mejor en este contexto. Expresadas por el propio traductor con cierta tosquedad e ingenuidad, con una casi siempre contenida humildad intelectual, en las antípodas del polemismo y la arrogancia de un notable contemporáneo como Enrique de Villena ${ }^{14}$, esta declaración del prólogo al Mostrador explicita una aproximación a su particular «método» de trabajo:

Ende, segunt la costunbre, oue a fazer de vn vocablo dos e de dos vocablos vno, e añader en algunt logar e menguar en otro, e en vno declarar e en otro acortar, e en otro poner la rrazon vocablo por vocablo tal qual esta; e mayor mente de la mejor trasladaçion, que es segunt yo e otros mas letrados espuesta e dada por muy mas notable. E muchas vezes tomo vn rrenglon de la vna trasladaçion e otro de la otra, e algunas vezes lo tomare tal qual esta,

${ }^{13}$ Sobre el Tostado véase: Hernández González, M.I., «A vueltas con Alfonso Fernández de madrigal y el Marqués de Santillana: De traducciones y comentos» en M.I. Hernández (ed.), En la teoría y la práctica de la traducción. La experiencia de los traductores castellanos a la luz de sus textos (siglos XIV-XV), Salamanca, SEMYR, 1998, pp. 71-105; Recio, R., «Alfonso de Madrigal: La traducción como teoría entre lo medieval y lo renacentista», La Corónica, 19/2 (1991), pp. 112-131. Para una visión de conjunto del contexto y la metodología traductológica cuatrocentista: Ruíz Casanova, J.F., Aproximación a una historia de la traducción en España, Madrid, Cátedra, 2000, pp. 90-95, 126-130.

${ }^{14}$ En su carta de presentación al rey Juan de Navarra de su traducción de la Eneida (1428), escribe Enrique de Villena: «Que cosa alguna non es dexada e pospuesta, siquiera obmetida, de lo contenido en su original, antes aquí es mejor declarada, y será mejor entendida por algunas expresiones que pongo acullá subintelectas, siquiere imprícitas, o escuro puestas, segund claramente verá el que ambas lenguas latina e vulgar supiere y ubiere el original con esta traslación comparado». Reproducida en Santoyo, J.C., Teoría y crítica de la traducción: Antología, Bellaterra, Universidad Autónoma de Barcelona, 1987, p. 32. 
por lo yo non entender segunt la trasladaçión este, non segunt debe. E por non errar, njn poner vno por al, helo de poner segunt esta enla dicha mejor trasladaçion ${ }^{15}$.

Pedro de Toledo traduce, según las técnicas de la época, usando como referencia las dos versiones hebreas anteriormente citadas. Para él, tal como confiesa, se trata de una tarea ardua y complicada porque no existe unanimidad ni en el fondo ni en la forma de estas traducciones y de otras versiones del mismo texto, «de quatro que fasta oy son» ${ }^{16}$. De modo muy general, en su valoración de las traducciones de Ibn Tibbón y de Al-Harīzī considera que, mientras que la primera es «mejor enla sçiençia», la segunda es «buena e conplida en lenguaje e muy sinple enla sçiençia» ${ }^{17}$. A lo largo y ancho del Mostrador, las glosas aclaran lo que la lectura del texto pone en evidencia: que Pedro de Toledo opta fundamentalmente por la traducción de Al-Harīzī , porque le resulta más asequible a la comprensión general del texto, pero que, sin embargo, se ve obligado a recurrir a la de Ibn Tibbón allí donde la complejidad del texto maimonidiano exige rigor terminológico y claridad conceptual. De hecho y sin negar esa prevalencia del trabajo de Al-Harīzī, como el riguroso análisis de Girón Negrón ha demostrado recientemente, de Toledo elige eclécticamente la traducción que mejor se amolda en cada momento a sus propósitos ${ }^{18}$. En la distinción que acabamos de citar arriba, el Tostado definía «interpretación» como la traducción que no añade glosas ni paráfrasis, si bien caben en ella los binomios léxicos o los desdoblamientos, siempre que no tengan tres palabras o más, es decir, por ejemplo, lo que Pedro de Toledo llama «fazer de un vocablo dos e de dos vocablos uno». La tensión entre el abbreviatio y el amplificatio, en la búsqueda de una mejor aclaración y dilucidación del texto original, parece que se expresa con claridad en el Mostrador con el tentativo "añader e menguar», «declarar e acortar», recurriéndose al estricto ad verbum al «poner la rrazon vocablo por vocablo tal qual esta e mayormente dela mejor trasladaçion», como tabla de salvación frente a las limitaciones hermenéuticas.

Todo traductor es siempre un intérprete de la obra que traduce. Pero, en el caso que nos ocupa, nos encontramos ante algo más. Producto de sus limitaciones filológicas, de una suerte de pudibunda autocensura, de la atención al beneficio pedagógico del

${ }^{15}$ fol. 1 .

${ }^{16}$ Junto a las dos traducciones mencionadas, Yosef Ibn Palquera, que vivió durante el siglo XIII, compuso el Môrèh ha-Môrèh ("Guía del Guía»), que es un comentario a la obra que incorpora la traducción de fragmentos de esta. Un estudio reciente sobre estas «notas» en Di Donato, S., «Notes on Shem Tov Ibn Falaquera as a Translator of the Guide of the Perplexed», Yod. Revue des Études Hébraïques et Juives, 22 (2019), pp. 155-182. Contemporánea a ésta encontramos, por último, una versión en forma de verso. Se trata de una traducción en verso a cargo de Rabí Mattityahu Kartin, mencionada en el compendio bibliográfico Sifte yeshenim, obra de Sabbatai Bass (1680).

${ }^{17}$ fol. $1 \mathrm{r}$.

${ }^{18}$ Girón Negrón, L.M., «Pedro de Toledo's Mostrador e enseñador de los turbados: The Christian Reception of Maimonides' Guide in Fifteenth Century Spain», en J. Stern, T. Robinson, \& Y. Shmesh (eds.), Maimonides' Guide, op. cit., pp. 141-179. 
destinario de la traducción, de reservas ideológicas o del simple desconocimiento intelectual, en aquellos pasajes del Môrèh en los que Pedro de Toledo no encuentra el término vernáculo preciso, despliega un original efecto de composición de incierta eficacia traductológica. En estos casos, transcribe la palabra original rodeándola de términos vernáculos que puedan hacerla comprensible. Así, por ejemplo, en el capítulo que dedica Maimónides, en la parte tercera de la Guía, al estudio de los sacrificios y las expiaciones encontramos, entre otras prescripciones, que «la fiera salvaje no puede servir nunca de sacrifico, ni la volatería para la oblación pacífica», y que Pedro de Toledo traduce: «porque non trayga corban de animalia, nin trayga ave de selamim», acompañado de la glosa al margen: «selamin es manera de sacrifiçio» ${ }^{19}$. 0 , también, más adelante, en el capítulo dedicado a las prescripciones sexuales de la vida matrimonial y a la tipología de las uniones no permitidas, allí donde se afirma «con el fin de apartarnos de las uniones ilícitas se prohibió al bastardo desposar a la hija de un israelita», el traductor castellano recoge que «para dispulsar delas fornicaçiones vedose echar al mamzer con fija de Yrrael», añadiendo al margen el notable «mamzerim, el que es engendrado con el mestruo» ${ }^{20}$.

En otros casos, al encontrar un término en apariencia desconocido lo transcribe tal cual. Así, por ejemplo, el Libro de los harutim designa literalmente en hebreo el Libro de las secciones cónicas, de Apolonio de Pérgamo (262-190 a. c) ${ }^{21}$. O, en este mismo sentido, cuando en el estudio sobre la justificación escriturística de Dios como Primer Motor, traduce «al que viene cabalgando por el desierto» (Sal 68,5) como «cavalgador en arabod $»^{22}$. Pero, también podemos encontrarnos en otros pasajes un curioso modo de resolución de las dificultades con las que el traductor se va encontrando en su empresa. En la conclusión del capítulo que Maimónides dedica al estudio filológico-exegético de los verbos šābat («descansar») y nûah («reposar») referidos a Dios, vincula semánticamente también la idea de descanso al concepto de nèfeš («alma»), afirmando al respecto que:

En cuanto al verbo wa-yinnāfaš, ('descansó'), es forma nifal (pasivo-reflexiva) de un denominativo de nèfeš. Ya dejamos expuesto que nèfeš es un polivalente que encierra el sentido de 'intención' y 'voluntad', y significa, por tanto, dicho verbo que su propósito se había cumplido y su voluntad quedaba del todo cumplimentada ${ }^{23}$.

Y que Pedro de Toledo traduce de esta guisa:

${ }^{19}$ fol. 127v. Guía III, 46 (45 en la versión de Pedro de Toledo, siguiendo la división de Al-Ḥarīzī). [רבץ (corbān), «sacrificio»; שלמים (selamîm), «oblaciones propiciatorias»]. Leemos en la versión אבל נשאר ענין 'החיה' וה'עוף' מפני שלא יבוא 'קרבן' מ'חיה' כלל ולא יקרב 'עוף' 'שלמים'. : אלמים (Todas las referencias de la traducción de Ibn Tibbón en: https://www.sefaria.org/Guide_for _the_the_Perplexed).

ממזר 'להתרחק מ'עריות' אסר לבעול “ממזר' 'בת ישראל. (mamzer), «bastardo»]. fol. 133v. Guía III, 49.

${ }^{21}$ fol. 44v. Guía I, 72. מרוט (jarutîm), «conos».

${ }^{22}$ fol. 34v. Guía I, 69. ערבות, ('arābôt), «desierto».

${ }^{23}$ Guía I, 67. La traducción en español utilizada en todas las citas es la de D. Gonzalo Maeso. 
Mas, el vocablo 'e folgo' es derivado de pasion del 'anjma', e que es dicho de 'uoluntad' e 'querer', e en muchas cosas, e sera su entençion e su manera aqui 'acabamiento de su uoluntat' e 'conpljmiento de su querer'24.

Con dificultades y de forma limitada traduce siguiendo la máxima ad verbum. Sin embargo, su propia insatisfacción le obliga a colocar una nota al margen en la que, cortando por lo sano, admite que la ininteligibilidad se ha colado en su traducción. De forma sorprendente, arguye en su defensa la supuesta superfluidad de aquello que no puede traducir: «nota que anjma es llamada nefes, e folgo es dicho vaynafas, que es çerca de nefes; e aqui se dexo un poco de gramatica abrayca que es ynposible rromançar, quanto mas eser en amas trasladaçiones estos dezires que son más mentira que verdat, nin su verdat cunple saber a vuestro eserviçio» ${ }^{25}$.

Esta época de traducciones muestra también en lo metodológico la notable importancia de la inculturación, un modo de adecuar el mundo de origen, referenciado en el texto base, al contexto presente. Esta estrategia, que implica inevitablemente una cierta transformación del original, ya era utilizada como exigencia por los retóricos clásicos. De acuerdo con Cicerón, verter como orador (el estilo ático) exigía conservar las sententiae y formae tamquam figurae, pero acomodándolas al uso de Roma ${ }^{26}$. Trasladados estos preceptos por la obra de San Jerónimo a la Edad Media, en el siglo XV se observa una acusada tendencia a sustituir instituciones de los antiguos por otras medievales y a cristianizar conceptos paganos. Pedro de Toledo no es ajeno a esta tendencia, pero, lo fascinante del asunto es que su tarea no es tanto transformar unos juegos circenses en justas de caballeros o a una vestal en religiosa que reza laudes, sino incorporar tal tendencia, en la España virulentamente antisemita de la época, a la traducción de una obra que tiene su origen en la aljama. Por ejemplo, el original (haandalusin) no es traducido por «los andaluces», sino por «los castellanos», aun cuando la intención de Maimónides es hablar de la opinión de «uno de los autores andaluces de obras médicas» ${ }^{27}$. En esta línea, también podemos encontrarnos que los nombres utilizados para ejemplificar cómo un atributo predica relaciones, Zayd, Umar, Bakr y Kalid, se convierten en "conocidos» nombres castellanos: "ca este Pedro eser conpañero de Johan e padre de Alfonso, e señor de Gonçalo e aparçero de Ferrnando, e morador en la casa que esta en tal logar, el que nasçio en tal año» ${ }^{28}$.

Ahora bien, donde la «diferencia» debe ser remarcada, mostrando una filiación que no conduzca a equívocos, es en el ámbito teológico y espiritual. Cuando, en las páginas finales de la parte I, el autor de la Guía critica la prueba de los mutakallimūn de la unicidad de Dios, mostrando su insolvencia (la necesidad de un agente que sustente la

\footnotetext{
${ }^{24}$ fol. $32 \mathrm{v}$.

${ }^{25}$ fol. 32v. Guía I, 67. וינפש (wa-yinnāfaš), «descansó» (Ex 31, 17); נפש (nèfeš), «alma».

${ }^{26}$ García Yebra, V., «¿Cicerón y Horacio preceptistas de la traducción?», Cuadernos de Filología Clásica, 16 (1980), p. 152.

${ }^{27}$ fol. 19r. Guía I, 42. ואמרו קצת האנדלוo' («alguno de los autores andaluces»).

${ }^{28}$ fol. 23v. Guía, I, 52.
} 
realidad del acto incluye la idea de imposibilidad; esta idea es ajena a la esencia de Dios como ajena es la idea de posibilidad, circunscritas ambas al ámbito del conocimiento humano), afirma que de la aceptación de tal concepto de posibilidad pudiera colegirse «que Dios no fuera no trino, como piensan los cristianos, ni uno, como pensamos nosotros $»^{29}$. Romanceado como «e quiça como piensan los xpistianos que son tres, e non es asi, que asi pensamos nos que es uno, e non es así», Pedro de Toledo añade un marginal con la intención, nos parece, de querer curarse en salud ante cualquier tipo de sospecha sobre su fe trinitaria, indicando, a la vez, una salvedad traductológica que induce a cierta confusión: «Nota del Hazeri onde diz quelos Christianos: e quiça dira alguno que es commo pensaron los Xristianos tres, e nos non pensamos asi si non que es vno, e non es asi la cosa segunt nuestro entendimjento, e esto es claro, e çetera $»^{30}$. ¿Por qué una referencia a la traducción de Al-Ḥarīzì como alternativa en este punto? Porque, aun siendo, como ya hemos comentado, el texto base de referencia en hebreo para el cuerpo narrativo de la traducción, allí donde las dificultades terminológicas evidencian las propias limitaciones de la versión de Al-Ḥarīzì, el autor opta por ceñirse en su literalidad a la versión de Ibn Tibbón. Pero, no sólo eso. Tal como el mismo Pedro de Toledo confiesa en una significativa glosa, en estos capítulos finales de la primera parte del Mostrador (72-76) opta en exclusiva por esta última versión, considerada «superior», para evitar más errores: «Sabed señor que por si mj libro muy errado, traslado todo lo mas del de Abentabon de aqui adelante, bueno o malo, porque la an todos por mejor trasladaçion $»^{31}$.

\section{Sobre sçiençia y contradezires}

Junto a las glosas, los prólogos y epílogos con los que el traductor enmarca su trabajo en las tres partes de la obra son una sugerente fuente de información sobre su propia idiosincrasia. También sobre sus competencias y limitaciones. ¿Cuáles son los galardones que exhibe Pedro de Toledo? ¿Qué universo de lecturas, qué visión del conocimiento, se desprende de todos estos comentarios? Nuestro traductor siente una enorme admiración por la Guía de perplejos, un respeto extraordinario por la figura de Maimónides. En el posfacio a la parte II del Mostrador podemos leer, como advertencia a «todo aquel que por este Libro estudiare», que si es alguien versado «en las artes, e en filosofia natural e moral e filosofia primera», debe saber que, hasta el día de hoy, no se ha escrito obra alguna como esta, «segunt en la manera que es e la sçiençia en que tracta, nin tal letrado sabio fue por esa manera en Judíos e Xristianos e Moros ${ }^{32}$. Esta consideración, unida a la certeza de estar enfrentándose a una obra monumental, le

${ }^{29}$ Guía I, 75.

${ }^{30}$ fol. 48 r.

${ }^{31}$ fol. 39v. Sobre este aspecto concreto, véase Girón Negrón, L.M., «Pedro de Toledo’s Mostrador e enseñador de los turbados: The Christian Reception of Maimonides' Guide in Fifteenth Century Spain», op. cit., p. 162.

${ }^{32}$ fol. $90 \mathrm{v}$. 
lleva a Pedro de Toledo a realizar una petición de carácter pedagógico al mentor y destinatario de la traducción, al señor Gómez Suárez de Figueroa: «e mandouos por via de dotrina delos maestros, que jamas non leades capitulo sin leer el ante del, que seria caso de vos fazer dubdar e non entender muchas cosas por la grant profundidat de este varon en este dicho libro» ${ }^{33}$.

En este mismo epílogo, el traductor también advierte sobre el carácter contradictorio de todo juicio superficial e interesado. Pero, sobre todo, parece prevenir al destinatario de su empresa frente a cualesquiera prejuicios ideológicos o culturales que pudieran poner en tela de juicio el valor y la oportunidad de traducir una obra como el Môrèh. ¿Quiénes pueden ser capaces realmente de entender una obra como esta, se pregunta, si, entre todos los sabios, sólo unos pocos han sido capaces de igualar tal profundidad y sutileza? Estos son, responde, «muy pocos e rralos, vno aqui en Europa, e otro en Asya, e otro en Africa». Con un tono de premeditada justificación que intenta alejar de sí y de su trabajo toda posible incomprensión, prejuicio u opinión contraria («contradezires non rrazonables»), aprovecha para recordar al lector sus conocimientos filosóficos y culturales. Muchas de las impugnaciones y críticas que se realizan en el ámbito intelectual, afirma, son el resultado de «çelos e enbidias», tal como nos recuerda Alejandro de Afrodisia, al que cita de forma arabizada como «Alfaradosi». Tal arabización de los clásicos, así como una no desdeñable presencia en las glosas de referencias al pensamiento islámico, ha hecho que algunos estudiosos atribuyan al traductor un cierto conocimiento del árabe ${ }^{34}$. En lo relativo a Afrodisia, suponemos, ya que no hay más indicaciones, Pedro de Toledo parece referirse al pasaje del Comentario al libro I de la Metafísica en el que Afrodisia habla de los celos de la divinidad a los hombres que poseen la sabiduría ${ }^{35}$. En un alarde de erudición, da cuenta de que de estas «yntençiones e malquerencias» ya nos advirtieron antes toda una nómina de ilustres pensadores árabes: «Abu Hamed Algazel en su libro que es El peso de las costunbres, e Abu

${ }^{33} \mathrm{Ibid}$

${ }^{34}$ Para Schiff el traductor no ignora esta lengua, puesto que cita con profusión en su forma árabe los filósofos a los cuales considera fundamentales, para él o para el propio Maimónides. Schiff, M., La bibliothèque du marquis de Santillana, Ámsterdam, Van Heusden, 1970, p. 443. Kaufmann se apoya literalmente en este aserto. D. Kaufmann, «Der 'Führer' Maimunis in Weltliteratur», en K. Wilhelm (ed.), Wissenschaft des Judentums im deutschen Sprachbereich (vol. 2), Tubinga, Mohr-Siebeck, 1967, p. 423. Ninguno aporta una justificación de esta afirmación, más allá de la recurrencia en la citación arabizada. Por su parte, Itzhak Bar-Lewaw concluye que Pedro de Toledo no domina el árabe y que su conocimiento del hebreo es limitado. Bar-Lewaw, I., «Pedro de Toledo, el primer traductor español del More Nebujim», op. cit., p. 62.

${ }^{35}$ Alejandro de Afrodisia, Comentario al Libro I de la Metafísca de Aristóteles, ed. W.E. Dooley, Alexander of Aphrodisias: On Aristotle Metaphysics 1, Londres, Bloosbury, 1989. «Por lo tanto, afirma, si lo que los poetas dicen acerca de lo divino fuera verdad -que siente celos de aquellos que son preminentes (y, por esta razón, también dicen que todos los que sobresalen y están por encima de los hombres débiles son desafortunados)- estaría aún más celoso de aquellos hombres que han alcanzado la sabiduría, porque ellos realmente poseen algo que trasciende su naturaleza mortal» (2, 18.1, pp. 37-38) (La traducción al castellano es nuestra). 
Faraje en sus dotrinas, e Mahomad Abu Zecaria, e Abu Naçer Alfarvi» ${ }^{36}$. Este conjunto de referencias encadenadas sobre la maledicencia y la crítica injusta, reverso de la supuesta humildad intelectual que preconiza el traductor, no deja de resultar sorprendente en un intelectual «cristiano» - por más que converso, casi con seguridadque, en este caso, dirige sus palabras a un noble castellano de alta alcurnia, hijo de un maestre de la Orden de Santiago, padre de un futuro obispo y fundador del monasterio de Santa María del Valle, en el que tomarán votos de clausura dos de sus hijas ${ }^{37}$. Sorprendente, porque, obviando la infinidad de referencias que la teología moral católica podía aportarle como ejemplo de rechazo a esos «contradezires non rrazonables» y a la envidia y maledicencia (detractio) ${ }^{38}$, Pedro de Toledo prefiere optar por lo que la escolástica árabe afirma al respecto, reforzando así la idea expuesta de cierto conocimiento de la lengua y la cultura islámica. Analicemos brevemente estas menciones, explícitas, aunque un tanto enigmáticas.

La única referencia bibliográfica aparentemente directa de las cuatro induce a una cierta confusión. ¿A qué obra de Al-Ghazālī (1058-1111) corresponde la citada como El peso de las costumbres? La parte segunda del extenso tratado Ihyā' 'ulūm al-dìn (Revivificación de las ciencias religiosas) está dedicada al estudio del «cuarto de las costumbres» (Rub'al-' ādāt), donde se analizan las costumbres mundanas y las normas de la vida diaria. Más cercana en su designación resultaría Mizān al-'amal (literalmente, La balanza de la acción), una suerte de primera versión o esquema preliminar del anterior. Conocida por los intelectuales judíos de la Península, esta obra algazeliana fue traducida al hebreo (Mozne Ședeq) en el siglo XIII por Abraham ibn Hasday (†1240), entusiasta partidario de Maimónides, autor de una ingente cantidad de versiones hebreas de textos árabes de autores islámicos y aljamiados de autores judíos, incluido el propio Maimónides ${ }^{39}$. La búsqueda entre sus páginas de un paralelo que pudiera justificar la cita de Pedro de Toledo es, sin embargo, harto difícil, más allá de declaraciones genéricas de una amplia aplicabilidad. Pero, habla a favor de esta referencia, su sentido ético y el que en ella se plantee el problema de la felicidad desde la óptica de la relación entre la ciencia y la virtud, los hábitos y las costumbres. De entre los distintos métodos para el acceso a la felicidad, el místico despierta el rechazo de los filósofos porque de él pueden derivarse ilusiones fantásticas y distintas clases de

${ }^{36}$ fol. $90 \mathrm{v}$.

${ }^{37}$ Cfr. de Salazar y Acha, J., La Casa del Rey de Castilla y León en la Edad Media, Madrid, Centro de Estudios, Políticos y Constitucionales, 2000, pp. 399-402.

${ }^{38}$ Así, Tomás de Aquino, S. T., IIa IIae, q. 73, a. 1; San Agustín: In Evangelium Ioannis Tractatus 44, 11.

${ }^{39}$ La primera edición moderna de esta traducción hebrea es Mīzān al-'amal: Compendium doctrinae ethicae, auctore Al-Gazali, ed. Jacob Goldental, Leipzig, Gerhardt \& Reisland, 1839. Sobre la significación ética del Mīzān, véase Garden, K., «Revisiting al-Ghazali’s Crisis Through his Scale for Action», en G. Turner (ed.), Islam and rationality. The Impact of al-Ghazali, Brill, Leiden, 2015, pp. 207227. Una aproximación a este contexto traductológico en Pearce, S.J., «The Arabe Sage Saids’: Transmitting Arabic Philosophy in Translation», en S.J. Pearce, The Andalusi Literary and Intellectual Tradition, Bloomington, Indiana University Press, 2017, pp. 149-170. 
opiniones. La traducción de la obra al hebreo y su circulación por las aljamas españolas bien pudiera justificar el conocimiento de esta por parte de Pedro de Toledo ${ }^{40}$. No ocurre lo mismo con el tercer ejemplo de homonimia vinculado a la cita del Mostrador que puede hallarse en el corpus algazeliano. Nos referimos al tratado lógico-filosófico alQisțās al-mustaqim (La balanza justa). En el primer capítulo, dedicado al estudio de las reglas del conocimiento, Al-Ghazālī narra la anécdota del encuentro con un polemista shi'í isma'ilí que, abrumándolo con dudas y críticas, le preguntó cuál era la balanza correcta para poder determinar la verdad del conocimiento, si la del razonamiento personal e independiente ( $a$ l-ra'y), la del conocimiento analógico (al-qiyass) o la del principio de autoridad ( $t a$ 'lim). Las dos primeras, afirmaba este interlocutor, son causa de «extremas contradicciones y equívocos, de desacuerdos entre los hombres»" ${ }^{41}$. Queda la duda, no obstante, de que una obra de estas características, claro ejemplo de polemismo interreligioso musulmán, hubiera podido tener difusión e interesar a los intelectuales judíos y cristianos de la Península en la baja Edad Media.

Por su parte, la mención de Mohamed Abū Zecaría no deja de ser también fuente de equívocos. Si optamos por plantear, hipotéticamente, que se trata de Mohamed Abū Zacaría Ibn al-Awwan (1158-?), esto permitiría afirmar que Pedro de Toledo poseía un conocimiento de la cultura de al-Ándalus más amplio de lo esperado. Abū Zacaría fue el autor de un importante y famoso tratado de agronomía (Kitāb al-Filāha), un compendio de los textos clásicos de la Antigüedad sobre la cuestión y de prácticamente todo cuanto había sido dicho por los andalusíes que se habían ocupado de este tema antes que él. En el prólogo del autor a esta obra encontramos un pasaje donde, tal vez, pudiéramos hallar ecos de la advertencia que nos hace el traductor castellano: «No atiendas pues a los dichos débiles del común de las gentes, ni te cuides de lo que dicen los ignorantes, apoyándote en lo que dicen erróneamente ${ }^{42}$. En contra de esta asignación estaría un dato determinante sobre el verdadero conocimiento del Kitāb al-Filāha por parte de Pedro de Toledo. Uno de los textos antiguos que es fundamento de este tratado de Abū Zacaría es el Kitab al-filaha al-nabatiyya (Libro de la agricultura nabatea), obra atribuida a Ibn Wahshîya. Escrita originalmente en lengua caldea, su verdadero autor responde al nombre de Kutsámi. Aunque la traducción arábiga de finales del siglo XI terminó eclipsando al original, Abū Zacaría se refiere a Kutsámi como el verdadero autor de la

${ }^{40}$ David Kaufmann, en su contribución al segundo volumen de Wissenschaft des Judentums, identifica El peso de las costumbres como «die bekannte Wage der Sitten oder Handlungen, im arabischen Urtext gelesen». Aunque categórico, no aporta ninguna justificación. En cualquier caso, en el mismo párrafo lee erróneamente del manuscrito «e Abu Faraje en sus dotrinas e Mahomad Abu Zecaria», identificando ambos como un solo autor, Ibn Bâjja (Aven Bâddja, Avempace): «Ibn Badja vollends als Mahomed Abuzecaria, d. h. als Sohn des Jachja». Kaufmann, D., «Der 'Führer' Maimunis in Weltliteratur», op. cit., p. 423. Una traducción reciente al alemán del Mizān al-'amal tiene por título Das Kriterium des Handelns (Darmstadt, 2006).

${ }^{41}$ Al-Ghazālī, al-Qisțās al-mustaqim, ed. D.P. Brewster, The Just Balance, Lahore, Ashraf Press, 1978, p. 2.

${ }^{42}$ Abū Zacaría, Kitab al-Filaha, ed. J.A. Barquerí, Libro de agricultura, Madrid, Imprenta Real, 1802, p. 2. 
obra y no al traductor. Maimónides cita dos veces el Libro de la agricultura nabatea en la Guía (III, 29) e identifica a Ibn Wahshîya como a su traductor. Por su parte, Pedro de Toledo traduce el título de la obra como «el libro del Serviçio Egipçiano, que saco el Moro Vasia» ${ }^{43}$ No parece, pues, poseedor de un conocimiento lo suficientemente profundo del Kitāb al-Filāha como para poder mencionar correctamente una de sus fuentes. Por último, complica aún más esta identificación otra homonimia distinta que se deduce de la siguiente glosa que encontramos en la parte tercera del Mostrador (III, 40): «Abu Zecarias declaró un pedaço del More e lo aprouo, e topo en una rrazon dudosa, e dixo 'esta rrazón busque quien gela declare'. E así digo, Señor, que estos capítulos, e mas este en espeçial, que busquedes quien vos declare» ${ }^{44}$. La nota, que corresponde a una aclaración insertada en el capítulo que la Guía dedica al estudio de los ordenamientos recogidos en el tratado Nezî́în («daños») del Talmud, no puede, evidentemente, referirse al agrónomo andalusí. ¿Quién es este Abū Zecarías? ¿Tal vez, Ali ben Zecarías, gaón de Bagdad a mediados del siglo XIII y vinculado de forma estrecha a la polémica antimaimonidiana en Oriente ${ }^{45}$ No es muy probable que Pedro de Toledo poseyera un conocimiento mínimo del mundo de las academias talmúdicas de Oriente, máxime cuando, tal como se advierte en las páginas del Mostrador, su propia tradición judía se le enajenaba en virtud de su condición de converso-hijo de conversos. Sin embargo, no tanto, para no poder citar, aunque fuera erróneamente, a Zeharía ben Isaac ben Še'alti'el Ḥen, activo en las décadas finales del siglo XIII. Médico, filósofo y hebraísta, Zeharía fue autor de numerosas traducciones y comentarios de obras de Aristóteles, Galeno, Avicena, Al-Fārābī y de Maimónides. Tradujo del autor de la Guía su tratado del acto sexual $\left(F \bar{i}-1-\right.$ jimä') y sus aforismos médicos $(F u s u ̄ u l ~ M u s a)^{46}$. Pero, lo que es más importante para nosotros, fue un intelectual comprometido con la difusión del Môrèh, un polemista activo en defensa del pensamiento maimonidiano desde un enfoque racionalista-naturalista y, en sintonía con esto, el autor de un comentario sobre los pasajes más intrincados de la obra ${ }^{47}$. De modo que, no parece descabellado relacionar este comentario y a su protagonista con ese Abū Zecarías que «declaro un pedaço del More e lo aprouo». Si optamos por esta hipótesis, dos son las vías hermenéuticas que se abren: «Abu Zecarias» es Zeharía ben Isaac ben Še'alti'el Ḥen y la opinión sobre los "contradecires non rrazonables», que se le atribuye se enmarca dentro de su vinculación general con la obra maimonidiana y la controversia de ella derivada, lo cual estaría justificado también por el contenido de la glosa anterior; «Abu Zecarias» designa

${ }^{43}$ fol. $112 \mathrm{v}$.

${ }^{44}$ fol. $120 \mathrm{v}$.

${ }^{45}$ Véase, Gil, M., Jews in Islamic Countries in the Midle Ages, Leiden, Brill, 2004, p. 468.

${ }^{46}$ Maimónides, On coitus, ed. G. Bos, Leiden, Brill, 2018. Contiene el texto arábigo original, tres traducciones hebreas, entre ellas la de Zerahía y dos versiones latinas editadas por Ch. Burnett; Maimónides, Medical Aphorism, Hebrew Translation by R. Zerahyah ben Isaac be She'atiel Hen, G. Bos (ed.), Leiden Brill, 2020.

${ }^{47}$ Un estudio de este en Fridman, J., «The Commentary on the Guide of the Perplexed by R. Zerahia ben Še'alti'el Ḥen», en Sh. Pines (ed.), Jacob Fridman Memorial Volume, Jerusalén, Hebrew University, 1974, pp. 3-14. 
a dos personajes diferentes, tanto a Abū Zacaría Ibn al-Awwan como a Zeharía ben Isaac, correspondiendo a cada uno de ellos, respectivamente, la primera y la segunda de las menciones insertadas.

Difícil resulta también la identificación, dentro de la vastísima producción de AlFārābī, de esta genérica alusión a las contradicciones intelectuales, a la crítica, a la disputa o a la envidia intelectual asociada a su nombre. En principio, es un dato conocido el que, en el tratado que el autor islámico dedica al pensamiento platónico, en la sección primera del mismo, afirma que «el hombre busca la perfección al margen de la envidia, pero la perfección que logra le hace objeto de la envidia de los otros» ${ }^{48}$. Esta reconocida traducción de Muhsin Mahdi, en cualquier caso, podría modificar un tanto el sentido estricto del texto original. La traducción de este pasaje, a partir de la edición árabe de A. Badawi, de Rafael Ramón Guerrero es la siguiente: «En primer lugar examinó la perfección del hombre en tanto que es hombre y qué cosa de las que tiene el hombre es aquella por la que llega a ser feliz, puesto que todo ser tiene una cierta perfección». La edición del texto árabe con su versión latina de Rosenthal y Walzer, confirmaría esto último ${ }^{49}$, quedando, pues, diluida la posibilidad de tal identificación. Más probable, tal vez, es que la referencia pertenezca al Kitāb al-tanbìh 'alā sabīl al-sa'āda, que fue traducido al latín como Liber exercitationis ad viam felicitatis, donde expresamente cita esos «çelos e enbidias» como afección del alma ${ }^{50}$.

Por último, más que fascinante es el rastreo de la mención a «Abu Faraje en sus dotrinas». Si se tratara de Abū-l-Faraj, Abulfaraj (897-967), el famoso escritor iraní, de origen árabe, autor de la célebre recopilación de poemas y cantos Kitāb al-Aghānī (Libro de los cantares), esta alusión podría estar relacionada con la descripción crítica de la moral social de su época, cosa bastante improbable. Sí que resulta más plausible el que se esté refiriendo a Abū al-Faraj 'Abd Allāh ibn al-Ṭayyib (†1043), conocido por su nombre latinizado Abulpharagius Abdalla Benattibus, escritor, sacerdote y polímato de la Iglesia Caldea. Contemporáneo de Avicena, entre sus obras filosóficas encontramos estudios y comentarios del corpus lógico peripatético. Su revisión crítica, desde postulados neoplatónicos, de la interpretación categorial de Alejandro de Afrodisia, su mención por parte de Maimónides y el hecho de que los judíos hispanos conociesen sus obras, dan fuerza a esta hipótesis ${ }^{51}$. Tampoco puede descartarse, como línea de

${ }^{48}$ Al-Fārābī, Philosophy of Plato and Aristotle, M. Mahdi (trad. y ed.), Ithaca, Cornell University Press, 2001, p. 59. Cfr. Colmo, Ch.A., Breaking with Athens: Alfarabi as Founder, Lanham, Lexington Books, 2005, pp. 58-60.

${ }^{49}$ Al-Fārābī, Las filosofías de Platón y Aristóteles, R. Ramón Guerrero (trad. y ed.), Madrid, Ápeiron Ediciones, 2017, p. 55; Falsafat Aflatun, Alfarabius de Platonis Philosophia, ed. F. Rosenthal y R. Walzer, Londres, Warburg Institute, 1943, (I-II, 10-15).

${ }^{50}$ Al-Fārābī, Kitāb al-tanbīh 'alà sabil al-sa'āda, en R. Ramón Guerrero, El camino de la felicidad, Madrid, Trotta, 2002, pp. 45-46.

${ }^{51}$ Mencionado de forma explícita por Maimónides en una de las versiones de la Epístola a Ibn Tibbón, lo califica, junto a otros intérpretes cristianos, como un lector en exceso servil y poco profundo de Aristóteles. Cfr. Marx, A., «Text by and about Maimonides», Jewish Quarterly Review, 25 
investigación aceptable, que el nombre de Abu Faraje corresponda a Gregorio Bar Hebraeus (1226-1286), obispo sirio-jacobita y polímato, el mayor representante del Renacimiento siriaco que tendrá lugar entre los siglos XII-XIII y cuya obra tuvo amplia repercusión en Occidente. Mencionado durante su vida en siríaco como Bar 'Ebrāyā, conocido en Occidente tanto como Abulfarag o Bar Hebraeus, al nacer recibió el nombre de Abū 'l-Faraj bar Ahron. Influenciado por Avicena y Al-Ghazālī, su obra reinterpreta la filosofía y la mística de estos autores a la luz de la teología y la mística cristiana. En este sentido, son evidentes los paralelismos entre su Ethikon y la Ihy $\bar{a}$ ' 'ulūm al-dìn (Revivificación de las ciencias religiosas) del pensador iraní, como también el que su Ktābā d-yawnā (Libro de la paloma) refleja de forma general un ideario moral donde resuenan ecos algazelianos. Leemos en este último tratado, en paralelo con el epílogo de Pedro de Toledo, un pasaje que nos recuerda a Ioannus Climacus y su 'E clímax Theías anódu' (Gradus ad Parnassum) y en el que se afirma que «la vanagloria, la envidia, la adulación o el rencor» son causa de rechazo del impulso divino y de alienación del hombre con respecto al mundo ${ }^{52}$.

Cerramos este análisis de las relaciones entre tradición, traducción y contexto en el Mostrador e enseñador de los turbados. Convertida por momentos la traducción del Môrèh en una suerte de espejo de príncipes que nos recuerda a la Visión Deleytable de Alfonso de la Torre (c.1410-1460?), Pedro de Toledo desliza una intencionalidad pedagógica que es, a su vez, una sutil expresión de gnoseología preventiva y de justificación manifiesta. Aquel que estudie a Rabí Moisés a partir de su versión romanceada, parece decir, debe saber que es necesario una lectura atenta, reflexiva y correlativa de la obra, por lo que pide a su señor -destinatario formal y material de su trabajo- y a todo aquel que a ella se acercara, recordamos, que «non leades capitulo sin leer el ante deel». La justificación se halla en la propia estructura de la obra y en un principio general formulado ya por Aristóteles en la introducción a la Metafísica, tal como Pedro de Toledo, nos dice, lee en su versión árabe o, probablemente, en una traducción de la misma: «Porque vos non maravilledes de lo que esta bien, por dos rrazones que Aristotiles diz en comienço de su Metafisica, segunt la trasladaçion morisca: la primera rrazon es por la profundidat de las sotiles e altas cosas, e la segunda rrazon por la cortidat e pequeño capaz de nos $»^{53}$.

(1935), p. 380. Sobre la variabilidad textual y el contexto de la epístola, véase Forte, D., «Back to the Sources: Alternative Versions of Maimonides' Letter to Samuel Ibn Tibbon and Their Neglected Significance», Jewish Studies Quarterly, 23 (2016), pp. 47-90.

${ }^{52}$ Book of the Dove, ed. A.J. Wensinck, Bar Hebraeus' Book of the Dove. Together with some Chapters from his Ethikon, Leiden, Brill, 1919 (I, 1, 525), pp. 5-6.

${ }^{53}$ fol. $90 \mathrm{v}$ (Epílogo). Leemos en Met. I, 982b: «Por ello cabría considerar con razón que el poseerla no es algo propio del hombre, ya que la naturaleza humana es esclava en muchos aspectos, de modo que -según dice Simónides- solo un Dios tendría tal privilegio». Aristóteles, Metafísica, ed. T. Calvo Martínez, Madrid, Gredos, 1994, p. 77. 


\section{En el mar de glosas del Mostrador}

En el ms. 10289 (olim-Kk9) pueden observarse dos tipos de glosas: unas son notas del traductor, copiadas con el texto por Alfonso Pérez de Cáceres; un segundo tipo de notas corresponden a una mano diferente de la del escribano, un personaje desconocido que las escribe probablemente unas décadas después de la culminación de la traducción ${ }^{54}$. Contienen precisiones lingüísticas, filosóficas y, de ahí su excepcionalidad, opiniones críticas de una inusitada contundencia e ironía. Marginales, interlineales, estas glosas son numerosísimas (1563 frente a las 45 del traductor hasta el fol. 20v, donde la voz del anónimo desaparece $)^{55}$. Este comentarista posee un conocimiento elevado del hebreo y del árabe. Es un crítico mordaz, un intelectual con la competencia necesaria para desentrañar exegética, teológica y filosóficamente el texto con el que se enfrenta. La capacidad con la que da cuenta de los textos talmúdicos y su dominio del hebreo hacen pensar con seguridad en un judío cercano al círculo del Marqués de Santillana $a^{56}$. Este glosador ejerce de traductor alternativo con rigor y contundencia. No sólo se rebela frente a la traducción, sino que, a veces, parece rebelarse contra el propio Pedro de Toledo, cuyo trabajo cuestiona abiertamente. Desde el folio uno al veinte, la capacidad intelectual, el conocimiento lingüístico, las decisiones sobre el texto que toma Pedro de Toledo, son puestas en cuestión de forma drástica. Habiendo abordado ampliamente la cuestión en otros trabajos anteriores, nos limitaremos en el presente estudio a dos ejemplos con el fin de ilustrar el necesario contrapunto que supone la obra de este anónimo en el estudio del romanceado de Pedro de Toledo.

La primera enmienda a la totalidad del trabajo del traductor la realiza este anónimo a cuenta del propio título de la traducción. Leemos al comienzo del prólogo de Pedro de Toledo: «El qual nonbre More quiere dezir: mostrador e enseñador delos turbados. Esto se entiende por los muy profundos Judios sabios en filosofía, que aujan dubda en sus coraçones, e fuertes turbaçiones de muchas cosas dela Santa Escriptura, que pareçian eser contra naturaleza e rrazon $»^{57}$. Con un claudator el anónimo señala su primera glosa, en la que afirma con autoridad: «verdad que More lo que quiere dezir es 'mostrador', mas non esto que dize delos turbados, que otro vocablo que dize en ebrayco hanebochim, aquel dize 'los turbados', e aun en la verdad nebochim en ebrayco 'desarados' quiere dezir, non commo el lo traslado, que el ebrayco de 'turbados' es nibhalim o mebohalim, mas esto pasadero es, segunt lo que tenemos en que entender adelante». La glosa indica una deficiencia en la traducción que es, hasta cierto punto, cuestionable. "Confuso» ${ }^{58}$, es en hebreo uno de los sinónimos de "perplejo» y se pueden usar

\footnotetext{
${ }^{54}$ Sobre la datación de estas glosas, véase Lazar, M., Pedro de Toledo's Mostrador, op. cit., p. XV.

${ }^{55}$ Notables del traductor por mano de escribano: Libro I: 95; Libro II: 20; Libro III: 72. Notables del glosador: 1563. Número total de notas en manuscrito: 1750.

${ }^{56}$ En este sentido, coincidimos con las opiniones de Bar-Lewaw y de Schiff. Cfr. Bar-Lewaw, «Pedro de Toledo, el primer traductor español del More Nebujim», op. cit., p. 61; Schiff, La bibliothèque du marquis de Santillana, op. cit., pp. 443-44.

${ }^{57}$ fol. $1 \mathrm{r}$.

נבוך (nebôk), «confuso».
} 
indistintamente, así como de «descarriado» (el «desarado» anónimo), «desconcertado», «extraviado» o «equivocado». En cualquier caso, al margen de las precisiones filológicas, lo determinante en la glosa es advertencia irónica sobre «eso que nos espera», es decir, la idea de la calidad de la traducción que una primera lectura le habría ya proporcionado al que ahora emprende la tarea de enmendar el texto. Expuestas una serie de justificaciones por el traductor en su prólogo, el glosador realiza unas contundentes anotaciones marginales en las que cuestiona la metodología y la competencia del primero. Leemos en este proemio: «E por quanto los traslados son diuersos e de diuersos letrados, buenos, e comunales, e njngunos. E los escriuanos otrosy todos por eser non letradost, erraron yerros manifiestos, yo lo que fiziere, sy errare non sea en culpa [...] quanto mas que amos trasladadores erraron* en muchas cosas [...] E muchas vezes+ tomo vn rrenglon dela vna trasladaçion e otro dela otra, e algunas vezes lo tomare tal qual esta, por lo yo non entender segunt la trasladaçion este, non segunt deueł». A lo que replica el anónimo en las glosas que hemos señalado:

$\dagger$ «Non son todos los escriuanos non letrados, nin todos erraron, njn mucho menos los trasladadores commo dize, segunt paresçera luego adelante, que el autor mismo vio la trasladaçion de Aben Tabbon, e la ovo por buena, avn que este trasladador diga que todos erraron, commo lo dize luego aquí adelante: que amos trasladadores erraron; mal sy penso descargar de si e cargar sobrellos». * «Saluo su graçia, que el mismo conponedor rraby Moysen de Egipto vio la trasladaçion de Aben Tabbon e la auctorizo; verdad es quela del Harizi es errada, e la suya mas [...] + Muchas vezes en esta mezcla el provecho es dudoso e el daño es çyerto, quando meno porque será mas trabajosa de adresçar. ¥Ya me paresçe que vyene en cognosçimyento que de neçesario ha de fallesçer en contrario de lo que ha dicho, que non fallesçera la entençion del autor» ${ }^{59}$.

La crítica que el glosador anónimo vierte en los márgenes del prólogo de Pedro de Toledo y que sostiene de modo fundamentado en sus sucesivas inserciones al texto, es una profunda impugnación del trabajo del traductor. ¿Cómo pueden justificarse las dificultades de la traducción en las deficiencias de los originales hebreos, plantea el anónimo, algo que sí podría objetarse a la traducción de Al-Harīīi, cuando existe una traducción «oficial», la de Ibn Tibbón, sancionada por el propio Maimónides? Para este comentarista, la opción metodológico-hermenéutica del traductor es contradictoria y no sirve para expresar la intencionalidad del original, ya que se basa en la combinación de una traducción tentativo-contextual, dada al circunloquio (Al-Ḥarīzī ), con una más literal y técnica (Ibn Tibbón), que cuida el rigor del vocablo, todo ello con el propósito

${ }^{59}$ fol. 1r. Podemos aventurar una explicación a la recurrente mención de los «errores de escribano». Junto al hecho de que estos errores eran algo habitual, comprensible y achacable a la limitación humana, el propio Maimónides comenta a Ibn Tibbón en la conocida epístola (incorporada al propio texto de la traducción, posteriormente, como un escrito cuasi canónico). Un dato del que no sería ajeno Pedro de Toledo: «Vi los lugares de nuestro extenso tratado que te han planteado dudas, y aquellos que te han sorprendido por los errores del escriba». Maimónides, Epistola a Shemuel Ibn Tibbón, op. cit., p. 114. 
de solventar el reto de una traducción que, tal vez, sea una empresa demasiado ambiciosa para él.

Hasta aquí la referencia a la singular batalla en glosa desplegada de forma diacrónica en la pura materialidad del texto. Ciñámonos, de nuevo, al estudio del romanceado de Pedro de Toledo y de sus notas a la traducción, insertadas, como ya hemos apuntado, por la misma mano que el texto, la del escribano Alfonso Pérez de Cáceres. De carácter explicativo y aclaratorio, a veces intentan aportar un poco de luz sobre aspectos terminológicos, filosóficos y teológicos, siendo, en la mayoría de los casos notas breves concernientes a la aclaración de voces y pasajes cuya comprensión resulta complicada o cuyo contexto cultural es ya distante. En otras ocasiones, son la expresión sincera o velada de las dificultades encontradas a la hora de traducir, quejas de Pedro de Toledo acerca de las dificultades de un trabajo tan arduo como el que ha emprendido. Todas ellas conforman una interesante suma de conocimiento y prejuicios. Casi siempre dispuestas en los márgenes del texto, estas glosas desaparecen progresivamente del texto en el tránsito de la parte primera a la parte segunda, reapareciendo, con una cierta profusión, en la sección dedicada por Maimónides en la parte tercera a la aclaración de preceptos rituales.

Con una cierta competencia en filosofía, aunque la comprensión de la tradición judía se le escape, allí donde la naturaleza filosófica del texto es relevante el traductor solventa de manera aceptable pasajes en los que es posible vincular la traducción a fuentes clásicas y a sus comentaristas islámicos. Por esta razón, creemos, en los veinticinco primeros capítulos de la parte segunda del Guía, aquellos en los que Maimónides realiza una síntesis de la cosmología aristotélica, el nivel de la traducción sube notablemente. Sin abandonar, en cualquier caso, el tono general de todos sus comentarios, encontramos a lo largo de toda la obra «notables» que corresponden a alguien, en principio, versado en filosofía. Cuando Maimónides aborda el estudio del antropomorfismo aplicado a Dios y la atribución a él de cualidades sensoriales (I, 47), afirma que las percepciones internas, a igual que las sensibles externas, se aplican a Dios, unas en sentido figurado y otras no. Pedro de Toledo, que traduce este pasaje, en primera instancia, de modo más que limitado («e asy se vsa enlos conosçimjentos jntrinsecos secretos, segunt vso enlos descubiertos alcançamjentos conoçidos»), incorpora una glosa que mejora notablemente el nivel filosófico de la traducción: «trasladaçion mejor: enlos conoçimjentos jntrinsicos, segunt aconteçe enlos conoçimientos sensuales jntrinsicos» ${ }^{60}$. Más adelante, en el estudio de las cinco clases de atributos positivos de los seres, de los cuales se excluye a Dios para evitar contradicciones, al ejemplificar los atributos predicados («cualidades») ajenos a la realidad y esencia divinas -no son cosa que la complete ni constituya- encontramos dos interesantes glosas. Un primer ejemplo de esta clase de atribución es cuando se califica a un ser humano cualquiera por alguna de sus capacidades intelectuales, morales o personales, todas ellas disposiciones del alma, algo que, afirma Maimónides, «está claro

\footnotetext{
${ }^{60}$ fol. $21 \mathrm{v}$.
} 
para cualquiera versado en la lógica» ${ }^{61}$. Pedro de Toledo incorpora una glosa en este punto en la que hace notar lo siguiente: «que eneste exenplo nonbro las dos que dize Aristotiles enlos 'predicamjentos' que son aujtuaçion e manera, enel primer genus de las cuatro qualidades; e el abito es fuerte de estar enla manera, ligera de quitar ${ }^{62}$. No cita a Maimónides, ni a su tratado lógico Maqālah fỉ Șinā'at al-Manțik, en cuyos dos primeros capítulos desarrolla la idea de predicación ${ }^{63}$. Tampoco al autor que es fundamento, junto al estagirita, de la teoría de las categorías maimonidiana, Al-Fārābīín sino que se va directamente a la fuente, a Aristóteles, y a su clasificación de las categorías. Leemos en el capítulo dedicado al estudio de la categoría de cualidad: «La palabra 'cualidad' tiene muchos sentidos. Admitamos que los hábitos y las disposiciones constituyen una clase de cualidad. Los primeros son distintos de las ultimas, en que, son más durables y estables» ${ }^{65}$. Hábitos y disposiciones, «aujtuaçion e manera», son, pues, distintas, pero conforman la primera clase («genus») de cualidades que distingue Aristóteles (junto a la capacidad e incapacidad natural, cualidades pasivas y afecciones y las formas y figuras de las cosas). Suponemos también al romanceador conocedor de la «nueva lógica» que, a partir del siglo XII, merced a las traducciones actualizadas al latín de las obras de Aristóteles había reemplazado a la «vieja lógica» representada por Boecio y sus traducciones de las Categoriae y De Interpretatione. Gracias a las traducciones de Jacobo de Venecia, Guillermo de Moerbeke y Petrus Hispanus, los tratados anteriores y sus comentarios se unen a una actualización del corpus lógico aristotélico con la traducción de los restantes libros de Organon aristotélico ${ }^{66}$. De hecho, las Summulae Logicales de este último se convertirán en manual de referencia para cualquier estudiante filosofía, profusamente copiado, editado y reditado hasta bien entrado el siglo XVII. En el tratado tercero de estas Summulae, "De los predicamentos», encontramos una exposición de la doctrina aristotélica al respecto donde se incide en la idea de mutabilidad asociada a la categoría de cualidad, en clara sintonía con la afirmación del romanceador ${ }^{67}$. Sin embargo, a pesar de esta aclaración, unas líneas más abajo en el texto, Pedro de Toledo no puede resistir la tentación en convertir de nuevo el conocimiento en disculpa. Ejemplifica Maimónides el tercer tipo de predicación, que

${ }^{61}$ Guía I, 52.

${ }^{62}$ fol. $23 \mathrm{v}$.

${ }^{63}$ Maimónides, Makalah fi-Sina'at al-Mantik, ed. I. Efros, «Mosheh ben Maimon. Maimonides' Treatise on Logic. The Original Arabic and the Three Hebrew Translations», Proceedings of the American Academy for Jewish Research, 8 (1966), pp. 34-38.

${ }^{64}$ Al-Fārābī, Kitāb al-qāṭāghūrīyās ayy al-maqūlāt, en D.M. Dunlop, «Al-Fārābī’s Paraphrase of the Categories of Aristotle», Islamic Quarterly, 4 (1958), pp. 168-197; 5, 1 (1959), pp. 21-54.

${ }^{65}$ Aristóteles, Las categorías, H. Giannini-M. I. Flisfisch (eds.), Santiago de Chile, Editorial Universitaria, 2016, pp. 79-80.

${ }^{66}$ Una descripción de esta empresa en Kneale-M. Kneale, W., The Development of Logic, Oxford, Oxford University Press, 1984, pp. 224-246; McKeon, R., «The Organization of Sciencies and the relations of Cultures in the Twelfth and Thirteenth Century», en J.E. Murdoch, The Cultural Context of Medieval Learning, Dordrecht/Boston, Reidel, 1975, 151-170.

${ }^{67}$ Pedro Hispano, Tractatus, ed. L.M. de Rijk, Peter of Spain: Tractatus, Called Afterwards Summule Logicales, Assen: Van Gorcum, 1972, pp. 27-35. 
comprende las cualidades afectivas o los sentimientos, simplificando el esquema aristotélico, y que el Mostrador traduce así: «Enxenplo terçero: diziendo del omne en calidades pasivas, asi commo: fulano se ensaño, o es piadoso, o temeroso, e deste genus es la sabor e la olor, e el calor e la frialdat, e la sequedat e umidat». Acto seguido, un marginal que pretende ser aclaratorio siembra dudas sobre lo que acabamos de leer: «en amas trasladaçiones me paresçen que non van rregladas las maneras de estas genus, que enel primero puso avjtuaçion e enel terçero la 'manera que es ligera de quitar', e turvome porque manera e avjtuaçion, amos an a eser juntos en vn genus, segun Aristótiles» ${ }^{68}$. ¿Qué está queriendo decir el traductor con esta glosa? Nos parece, fundamentalmente, que dos cosas en una: que ante las dificultades con las que se enfrenta, traduce obviando la versión hebrea, incluso la más rigurosa en el uso de los términos técnicos, la de ibn Tibbón; y que, de algún modo, lo que hace es dejarse llevar, en el fondo, por la inercia de la versión latina de Aristóteles que maneja o conoce de las Categorías. Siguiendo a Aristóteles, ejemplifica la predicación de «cualidades pasivas», a diferencia del texto hebreo que habla de una «cualidad afectiva o los sentimientos»" pero, además, lo hace mal. Por un lado, traduce en la glosa (que no en el texto, donde lo obvia) «enla manera, ligera de quitar» en vez de «sin que sean cualidades permanentes» ${ }^{70}$, confundiendo esa «manera» con la idea de la «disposición» que posee el hombre en cuanto ser animado («puro», «navegante», «sano»). Por otro, parece ignorar, a pesar de su filia aristotélica, que el estagirita afirma no sólo en Categorías, sino también en la Física, que las cualidades pasivas no se dan en todas las especies de cualidad, sino en esta tercera clase ${ }^{71}$.

Mediante estas glosas el traductor pretende guiar al destinatario del romanceado por los pasajes más obscuros del Môrèh; también, supuestamente, hacer gala de una capacidad intelectual a la altura de la empresa que aborda. En un pasaje en el que Maimónides explica que la doctrina del tetragrámaton divino es inaccesible al intelecto humano sin el concurso del Intelecto activo, tal como afirma la ciencia de la metafísica ${ }^{72}$, el traductor inserta la siguiente glosa: «non se puede entender esto bien sinon con lo que diz enel 'Libro del anima' e 'Cartas de Aben Ruyz'» ${ }^{73}$. Como sabemos, «Aben Ruyz» es el modo castellanizado con el que en los siglos XV y XVI se designa a Abū IWalīd'Ahmad ibn Rušd, Averroes. Las obras de Averroes a la que se refiere Pedro de Toledo son, suponemos, el comentario mayor al De anima aristotélica y la Epistula ad amicum. En este sentido, podemos aventurar que Pedro de Toledo entiende en un sentido averroísta ese «e lo que aprendio firme en su mano», es decir, el pasaje de la

${ }^{68}$ fol. $23 \mathrm{v}$.

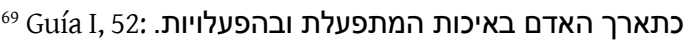

${ }^{70}$ Ibid. כשלא יתחזקו המדות

${ }^{71}$ Cat. VIII, 8b26, 10-16; Phys. VII.3, 245b3-246a9

${ }^{72}$ Guía I, 62.

${ }^{73}$ fol. 30v. Aben Ruyz es el modo castellanizado con el que en los siglos XV y XV se denominaba a Abū I-Walīd Ahmad ibn Rušd, Averroes. La obra de Averroes a la que se refiere Pedro de Toledo es el comentario mayor al Acerca del alma de Aristóteles. 
Guía donde se afirma que «su instrucción se conserva en él», a saber, que no es posible prescindir de la percepción del Intelecto agente. Afirma Averroes al respecto: «Cuando el entendimiento en potencia llega a su perfección, la inteligencia agente se une a nosotros. Gracias a ella entendemos las cosas abstractas y hacemos que los sensibles sean entendidas en acto, en la medida en que ella se hace forma en nosotros» ${ }^{74}$. En la Epistula, por su parte, Averroes afirma en línea con lo anterior que «Dios conoce las cosas por el mismo hecho que ellas le deben a él su origen; las conoce porque es sabio» ${ }^{75}$. Desvelar, a partir este punto, la comprensión que pudiera tener de Toledo -si es que la tuvo, cosa más que improbable- de las diferencias entre Averroes y Maimónides en relación a la concepción del Intelecto agente, se nos antoja una tarea imposible, tanto desde una lectura del texto como a partir de las glosas, que no advierten nada al respecto.

Las referencias peripatéticas son una constante en las glosas de Pedro de Toledo, tal como puede comprobarse. Al ser abordadas las relaciones entre cosmología y ontología desde el estudio del puesto del hombre en el universo, Maimónides realiza una pormenorizada descripción de la influencia del movimiento de las esferas en los procesos de transformación de los elementos sublunares. En la descripción de esta mecánica del universo afirma que «la materia de todo ese quinto cuerpo, dotado de movimiento orbital, no es como la de los cuatro elementos contenidos en su interior ${ }^{76}$. La traducción reza: «e la materia deste todo quinto cuerpo, que se mueue en çercualidat, non es commo la materia delos cuerpos delos quatro elementos que dentro son». Un marginal didáctico aclara, a continuación, la noción del quinto elemento que conforma todas las esferas que rodean la tierra y la referencia para su estudio: «Aristotiles en los Metauros llama el çielo quinto elementos» ${ }^{77}$. Pedro de Toledo se refiere a los Meteorológicos ${ }^{78}$. No es, en cualquier caso, una aportación excepcional. Traducido el tratado por Gerardo de Cremona al latín y por Samuel ibn Tibbón al hebreo, a partir de las versión arábiga, en el siglo XII, la nova traslatio de Guillermo de Moerbeke (1260), directamente del griego, le dio vida renovada y amplísima difusión. De hecho, la Meteorologica o Meteora aristotélica se convertirá en una obra escolar de divulgación,

${ }^{74}$ GC III 36, 483:124. Montada, J.P., «Averroes: Comentario mayor al libro Acerca del alma de Aristóteles. Traducción parcial», Anales del Seminario de Historia de la Filosofía, 22 (2005), pp. 65-109.

${ }^{75}$ El tratado breve Damima fue traducido en 1278 por Ramón Martí con el título Epistula ad amicum, incorporándolo en el Pugio fidei (I, 25). La cita está tomada de la traducción íntegra del texto en Alonso, M., Teología de Averroes, Sevilla, Universidades de Córdoba, Málaga y Sevilla y Fundación del Monte, 1998, p. 364.

${ }^{76}$ Guía I, 72.

${ }^{77}$ fol. $38 \mathrm{v}$.

${ }^{78}$ Meteor. I, 3 (Estudio de los elementos sublunares y la influencia del cielo sobre ellos). 
materia obligada de estudio, por ejemplo, en las universidades italianas a principios del siglo $\mathrm{XV}^{79}$.

Más interesante resulta otra inserción aclaratoria que encontramos en la segunda parte del Mostrador. En la refutación maimonidiana de la teoría aristotélica de la creatio ex nihilo, se cita un largo fragmento del libro segundo de la Física en el que el estagirita critica que el mundo hubiera podido surgir fortuitamente, sin una causa ${ }^{80}$. Concluye Maimónides el párrafo afirmando que «tales son sus palabras, que corrobora con extensos pormenores para demostrar la falsedad de tales cavilaciones» y que Pedro de Toledo traduce de modo no excesivamente elegante así: «e este fue el su dezir e ya desfizo este suzio pensamiento muy largamente». A continuación, añade la siguiente glosa: «Conviene a saber Aristotiles en el segundo de los Físicos, onde prueva la causa final en todas las cosas naturales» ${ }^{81}$. El efecto de esta prueba de erudición, que casi permite disculpar el pobre contexto traductológico del que brota, parece, a continuación, diluirse y sostenerse a la vez. Afirma Maimónides que no parece comprobado, tal como puede leerse en el libro segundo de la Física, que, en el caso de los seres nacidos por generación espontánea, Aristóteles afirme que «haya de seguirse de necesidad que sean fruto de un designio y de una voluntad libre» ${ }^{82}$, ya que identificar como la misma cosa la existencia por necesidad y el nacimiento en virtud de un designio, "parece poco menos que la combinación de dos contrarios» ${ }^{83}$. Con suma dificultad, Pedro de Toledo traduce «Mas que se siga, por non ser de si mesmos, que son por entençion de voluntador $(*)$, non me dira onbre el eser por via neçesaria e entre la ynouaçion por via voluntaria, fasta que sean amas cosas una $(\dagger)$, mas çerca es a mi ajuntamento entre dos contrarios», intercalando, a continuación, estas dos glosas en este breve texto: $\left(^{*}\right)$ «nota que estos dezires son muy nobles en abrayco, e en rromançe, en contrario, non puede al ser»; $(\dagger)$ «Onde diz Avu Naçer saber que qué en se entiende por dos cosas contrarias, onde es la rrazón muy profunda e ha menester gran estudio» ${ }^{84}$. Como un pábilo vacilante, en el Mostrador el conocimiento ilumina a la vez que se ahoga, empañado por la confusión y la disculpa. Pedro de Toledo nos recuerda su conocimiento de la escolástica islámica, de la filosofía de Al-Fārābīy de un punto esencial de la misma, la distinción lógico-metafísica entre la esencia y la existencia de los seres creados. Hay seres posibles. Su esencia no implica la necesidad de su existencia y su existencia posible, exige de la existencia de otro ser, necesario, que garantice la concreción de

${ }^{79}$ Cfr Goyens, M., de Leemans, P., Smets, A. (eds.), Sciencie Translated. Latin and Vernacular Translations of Scientific Treatises in Medieval Europe, Lovaina, Leuven University Press, 2008, pp. 162164.

${ }^{80}$ Phys. II, 4, 196a, 25-35.

${ }^{81}$ Guía II, 20; fol. 68v.

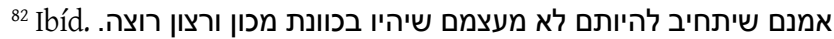

קרוב אצלי לקיבוץ בין שני ההפכים.

${ }^{84}$ fol. $68 \mathrm{v}$. 
dicha posibilidad ${ }^{85}$. Pero ¿se refiere realmente Maimónides a eso en el texto? ¿Cuáles son los contrarios cuya contradicción es insostenible? El texto del original, como hemos visto, habla de la distinción entre «necesidad» y "designio», que Pedro de Toledo convierte en la distinción "via neçesaria- via voluntaria», a partir del concepto de «ynouaçion», que es como él cree entender la idea de "espontaneidad». No parece comprender el traductor que, en el fondo, lo que se está dirimiendo en estas páginas de la Guía es una concepción cosmológica y que Maimónides trata de refutar la necesidad y el determinismo implícitos en el pensamiento de Aristóteles y, también, en el de AlFārābī. Sin embargo, también podría estar queriendo decir en esta glosa a cuenta de AlFārābī algo diferente de lo que creemos leer en ella, una indicación más sencilla y literal: que debe estudiarse la lógica de Al-Fârâbî para entender el principio de nocontradicción y el correcto uso de la afirmación proposicional, de las reglas silogísticas que protegen al conocimiento de cualquier error conceptual, a través de las cuales la prueba conceptual queda al margen de la contradicción ${ }^{86}$.

\section{A modo de conclusión: elogio de la disculpa}

Fijémonos en la primera de las dos glosas anteriores: «Que estos dezires son muy nobles en abrayco, e en rromançe, en contrario, non puede al ser» ${ }^{87}$. Supongamos que el amanuense traslada anotaciones y explicaciones del propio traductor, Pedro de Toledo. A través de esas notas parece descubrirse un cierto grado de insatisfacción, una mirada dubitativa y ansiosa hacia lo ya realizado, hacia el proceso de traducción. A Pedro de Toledo no le bastan las disculpas que llenan el prólogo, no le satisface el recurso a una traducción que, a veces, es tentativo-intuitiva y que se sirve de dos o tres términos para intentar captar conceptualmente el concepto original de Maimónides. En ciertos momentos es como si percibiera que lo que está traduciendo, si bien puede ser puesto en castellano, no parece, en cambio, que pueda someterse a otra racionalidad diferente de la cultura-lengua original. Una permanente sensación de provisionalidad gravita en torno al traductor. Raras veces contento de su trabajo, expresa sus sentimientos y percepciones con una actitud donde el sincero pesar se mezcla con una acusada y servil tendencia a cargar la responsabilidad del posible error a otros, o a dificultades de tipo material ajenas a él: «nota non me pareçe que este capitulo vaya amj voluntat, por la error que falle en $\mathrm{mj}$ libro, mas fize lo que pude» ${ }^{88}$, o bien: «por la error de mj libro non es este capitulo muy

${ }^{85}$ Un análisis de la cuestión, desde las relaciones entre Al-Fārābī y Maimónides, en Fackenheim, E.L., "The Possibility of the Universe in Al-Farabi, Ibn Sina and Maimonides», Proceedings of the American Academy for Jewish Research, 16 (1947), 39-70.

${ }^{86}$ Al-Farabi, Ihșā al-'ulūm, 53. 5-9, ed. A. Galonnier, Le De Scientiis Alfarabii de Gérard de Crémone: Contribution aux problèmes de l'acculturation au XIIe siècle (édition et traduction du texte), Turnhout, Brepols, 2017.

${ }^{87}$ fol. 68v.

${ }^{88}$ fol. 11 r. 
aderesçado y non pude mas» ${ }^{89}$. Los casos se repiten y refuerzan la impresión que transmite la traducción en su conjunto: que su enorme valor como hito histórico-cultural queda empañado por las evidentes limitaciones intelectuales del traductor. En la glosa que sigue, por ejemplo, Pedro de Toledo estaría dando a entender, aparentemente, que puede contrastar el original judeo-arábigo (cosa casi improbable), con las traducciones hebreas que maneja, un conocimiento del original desde el que sólo sería aceptable un aserto como este: «Nota que este capitulo enlo mas estan erradas anbas trasladaçiones, son erradas en trasladaçion, e gran yerro de ellos estos». Sin embargo, para alguien que dominara el original, la opinión negativa de las traducciones hebreas no debería suscitar la confesión, acto seguido, de tan particular turbación: «e ay turbamiento en el rromançar, e non se puede al fazer por que sepa mj señor la verdat, ca non so contento poco njn mas $»^{90}$.

Este tipo de glosas son una constante en toda la traducción y despiertan en el lector, cuanto menos, una duda razonable. Por un lado, evidencian aquello que el traductor conoce, el conjunto de sus lecturas, la propia materialidad literaria de las traducciones de las que se sirve. Junto a ello, estas notas son, como ya hemos visto, un modo de justificar su opción metodológica, donde la fidelidad y el rigor terminológico se abandonan, a veces, por una ecléctica superposición de literalidad, omisiones y recurso al circunloquio que bien pudiera definirse como «tentativa traductológica». Pero hay algo más. Si Pedro de Toledo no dominaba o desconocía el original Dalālat al-ha'îrim, lo cual convierte en absurda su impugnación parcial de las traducciones de Al-Harīzī y de Ibn Tibbón, hubiera tal vez podido suplir sus limitaciones con una referencia a otras versiones del texto maimonidiano, en este caso a algunas de las versiones existentes en latín ${ }^{91}$. No parece, sin embargo, ser el caso. La versión latina del siglo XIII, Dux neutrorum, que presenta la limitación de su fuente -el texto de Al-Harīzī - en lo relativo a la terminología científica, habría sido, no obstante, un buen apoyo desde el que solventar aquellos pasajes complejos desde un punto de vista expositivo-narrativo. Por el contrario, lo que advertimos en la traducción y en su diálogo con las glosas por mano de escribano, es que estamos más ante una traducción que se aferra radicalmente al ad verbum allí donde se siente incapaz, que en muchas ocasiones es una copia cuasi material del original hebreo, que ante un riguroso ejercicio crítico de insatisfacción traductológica erudita. Hay momentos en los que el traductor, en comentarios cargados de emotiva sinceridad, se justifica casi con un sentimiento de impotencia. A su señor Gómez Suárez le confiesa: «Señor, non puede al fazer, que amas trasladaçiones en esto son tales que non an seso nin rrazón rromançadas, e rresçebid lo que mejor puedo, que

${ }^{89}$ fol. $12 \mathrm{v}$.

${ }^{90}$ fol. $22 \mathrm{v}$.

${ }^{91}$ Así, la versión latina datada en la segunda mitad del siglo XIII Dux neutrorum, basada en una combinación de traducción literal y de paráfrasis del texto de Al-Ḥarīzī. Cfr. Di Segni, D., «Literal and Non-Literal Translation in Maimonides' Dux neutrorum», Yod. Revue de Études Hébraïques et juives, 22 (2019), pp. 13-48. 
non puedo más» $\cdot{ }^{92}$ Un lamento que se suaviza en algunas de las contadas ocasiones en las que Pedro de Toledo da a entender que está satisfecho con su labor, satisfacción esta compartida también de modo más que sincero: «este capitulo es de los profundos capitulos deste libro, e non ay error salvo si fuer del escrivano» ${ }^{93}$. Consciente de la diferencia entre el hebreo que conoce y el romanceado al que aspira, parece buscar una escrupulosidad que disculpe el fracaso de su empresa: «por quanto este capitulo non es bueno en amas trasladaçiones, puselo tal qual es, sin aderesçamiento de vocablos, por non errar mas de lo que el mesmo es mal aderesçado ${ }^{94}$.

Cuando la Guía de perplejos aborda en su parte tercera la hermenéutica de la Ley y de algunos de sus de preceptos, una notoria incomodidad se adueña del traductor, recurriendo a glosas y anotaciones en las que pareciera querer decirnos: «eso son cosas de judíos» o «este no es un tema sobre el que yo sea competente». En sintonía con esto, encontramos también en todo el texto una acusada tendencia a acortar las citas bíblicas y, sobre todo, las talmúdicas. Un ejemplo de esto es cómo Pedro de Toledo muestra su reparo ante preceptos higiénicos relativos a la moral sexual. En el análisis que Maimónides realiza en la tercera parte del Môrèh sobre las imperfecciones de la materia, aduce con orgullo que uno de los motivos de santidad de la lengua hebrea es la inexistencia de vocablos que den cuenta de los órganos de la copulación, del acto de la generación, esperma, orina, etc. ${ }^{95}$. Todos los términos hebreos al respecto son alusivos. Pedro de Toledo, omite toda una extensísima lista de ejemplos, que ocupan quince líneas del texto, con un "e así las otras cosas viles de fabla», colocando el siguiente notable: «En este capítulo ay cosas astrosas de se escreujr pocas e otras que non montan, que pareçen burla enel rromançe, e por eso las abreuje, mas non falleçe del capítulo cosa» ${ }^{96}$.

Terminamos. En el estudio conclusivo de la Guía de perplejos encontramos la famosa «parábola del rey en su palacio». En ella afirma Maimónides que la Providencia divina se derrama sobre los hombres en función del intelecto. Los más alejados del Dios providente, aquellos que se hallan «fuera de la ciudad», son esos «que no tienen ninguna creencia religiosa, ni especulativa ni tradicional ${ }^{\diamond 7}$. Pedro de Toledo traduce el pasaje de este modo: «los varones que son fuera dela çibdat es todo aquel que non tien creençia de ley, njn tiene estudio, njn cosa por via de cabala». Y añade el siguiente marginal: «cabala, es cosa rresçebida fijo de padre, e padre de abuelo, fasta Moysen $»^{98}$. El traductor expresa a medias la idea maimonidiana -carecer de creencia religiosa, ya sea esta tradicional o racionalista- diferenciando y simplificando este binomio en tres

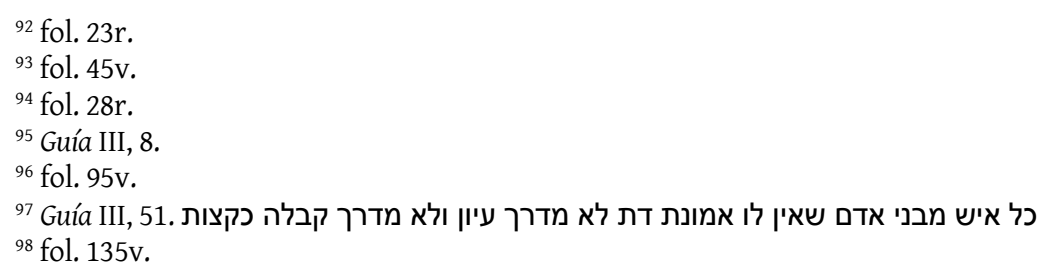


posiciones con respecto a la fe que se solapan mutuamente: fidelidad a los mandamientos, estudio (suponemos de esos preceptos) y sintonía con la Tradición. Sin embargo, una sutil paradoja identitaria creemos ver reflejada en medio de esta limitada comprensión. Partícipe de un universo cultural y espiritual atribulado, la peculiar idiosincrasia de Pedro de Toledo le permite identificar «tradición» correctamente con "cábala», hasta el extremo de trasvasar directamente el término hebreo al texto. Aproximadamente dos décadas después del fin de la traducción del Mostrador, otro posible converso, Alfonso de la Torre, afirmará en la Visión Deleytable que los secretos de la cábala («lo de los nombres») sólo pueden ser desvelados frente al «espejo de la verdad», unos secretos casi igual de importantes que los de la profecía ${ }^{99}$. Se trata de una correcta atribución del significado secundario del término hebreo, máxime en el contexto de la exposición de una doctrina esotérica, que es en el que Alfonso de la Torre lo usa. Como estricta, correcta y literal, nos parece, es la atribución de Pedro de Toledo, desde la acepción primaria de "cábala», tan ceñida a la concepción rabínica y a su cadena de transmisión como estas palabras de Abraham ibn Daud de Toledo: «El propósito de este Libro de la Tradición (Sefer ha-Qabbalah) es dar a conocer a los discípulos las enseñanzas de nuestros maestros, los sabios de la Mishná y el Talmud ${ }^{100}$.

José Antonio Fernández López joseantonio.fernandez13@um.es

Fecha de recepción: 09/06/2020

Fecha de aceptación: 13/08/2020

${ }^{99}$ Visión Deleytable I, 28. A. de la Torre, Visión Deleytable, ed. J. García López, Salamanca, Ediciones Universidad de Salamanca, 1991.

100 A. Ibn Daud, Sefer Ha-Qabbalah, ed. G.D. Cohen, The Book of Tradition, Filadelfia, Jewish Publication Society of America, 1967, p. 3. 
